\title{
Cardiovascular Risk and Metabolic Syndrome in Individuals with Mental Disorders
}

\author{
Sarah de Melo Rocha Cabral ${ }^{\circledR}$ and Marize Melo dos Santos ${ }^{(\mathbb{1}}$ \\ Universidade Federal do Piauí (UFPI), Teresina, PI - Brazil
}

\section{Abstract}

Background: Patients with mental disorders are more susceptible to cardiovascular diseases and metabolic disorders compared to the general population.

Objective: To evaluate cardiovascular risk and metabolic syndrome in individuals with mental disorders.

Materials and methods: A cross-sectional study, conducted at the Psychosocial Care Centers. Socioeconomic, clinical, biochemical and anthropometric data were collected using a standard form. Cardiovascular risk was assessed by the Framingham risk score. Metabolic syndrome (MS) was determined by the World Health- Organization (WHO), the National Cholesterol Education Program (NCEP) and the International Diabetes Federation (IDF) criteria. Data were analyzed by descriptive statistics, and associations were evaluated by the chi-square test and Fisher's exact test, as well as Odds Ratio. The significance level adopted for all statistical tests was 5\%.

Results: The chance of individuals diagnosed with MS be at intermediate-to-high cardiovascular risk was greater (12.22, 8.01 and 6.23 times higher according to WHO, NCEP and IDF criteria, respectively) than those without MS.

Conclusion: A high percentage of patients with mental disorders were at intermediate / high cardiovascular risk, and this was significantly associated with MS. (Int J Cardiovasc Sci. 2019;32(5):517-523)

Keywords: Cardiovascular Diseases/physiopathology; Mental Disorders; Metabolic Syndrome; Mental Health; Patient Care Team Psychosocial Support Systems.

\section{Introduction}

Psychiatric reform in Brazil was implemented with the objective of changing the model of mental health assistance from a hospital-centered one to a communitycentered model, based on the principles of the Brazilian Unified Health System and focused on a humanized psychosocial rehabilitation. ${ }^{1}$ The Psychosocial Care Centers (CAPS) have become the main actors in this process, providing multidisciplinary care, social interaction, active participation of the families, ${ }^{2}$ and sociocultural inclusion of patients by intersectoral actions. ${ }^{3}$

Studies have reported that individuals with mental disorders (MDs) are more likely to develop metabolic syndrome (MS) and coronary disease, especially due to poor access to a well-balanced diet and physical exercise, and also to pharmacotherapy, mainly psychotropics. ${ }^{4,5}$
Metabolic syndrome is composed by several conditions, many of them commonly seen in MD patients, including hypertension, glucose intolerance, visceral fat accumulation, and dyslipidemia. Together, these factors have a negative impact on metabolism, increasing the risk for type 2 diabetes mellitus and cardiovascular disease, and affecting patient's quality of life. ${ }^{6}$

Metabolic syndrome has gained much attention not only because of the high prevalence of its components, but also because of their association with cardiovascular risk. The syndrome is associated with a risk two times greater for cardiovascular diseases, such as infarction, stroke and cardiovascular mortality. ${ }^{7}$ Grover et al., ${ }^{8}$ and Speyer et al., ${ }^{9}$ confirmed the high prevalence of cardiovascular risk factors and MS in MD patients, and reported premature death in this population, especially among schizophrenic patients. 
In the present study we evaluated cardiovascular risk and MS in individuals with psychiatric disorders attending CAPS in the city of Teresina, Brazil.

\section{Methods}

This was a cross-sectional, analytical study conducted from October 2015 and February 2016.

The sample was composed of 729 individuals of both sexes, older than 18 years, that attended weekly CAPS of Teresina, Brazil, as part of the multidisciplinary treatment program. The sample size calculated to allow estimation of the parameters with an error margin of 5\% and 95\% confidence level was 298 participants. The sample was selected using Thompson parameters, by simple random sampling (shuffling) and proportionally stratified according to the district zone.

The eligibility criteria were the presence of the tutor and/or caregiver with the patient and agreement with participation in all phases of the study - 1) interview for the collection of sociodemographic (sex, age, race, educational level, family situation and income) and clinical (psychiatric diagnosis and smoking status) data; 2) blood sample collection for laboratory measurements (glucose, HDL cholesterol, LDL cholesterol and triglycerides); 3) obesity-related anthropometric measurements (weight, height, body mass index - BMI - waist circumference, abdominal circumference, hip circumference, waist-to-hip ratio - WHR); and 4) blood pressure measurement.

Patients who did not attend CAPS weekly, who received medical care seen at home, pregnant women or those with previous pregnancy in the last six months were considered ineligible.

Diagnosis of psychiatric disorders were grouped into eight categories according to the International Classification of Diseases ICD 10: F00-F09 Organic Mental Disorders; F20-F29 Schizophrenia, schizotypal disorder, and persistent delusional disorders; F30-F39 Mood (affective) disorders; F50-F59 Behavioral syndromes; F60-F69 Disorders of adult personality and behavior; F70-F79 Intellectual disabilities; F80-F89 Psychological Developmental Disorder; and unspecified ICD-10 codes.O, ${ }^{10,11}$ In case of two or more diagnoses, we considered the first diagnosis recorded in the medical records.

Smoking was defined as any smoking, i.e., independent of the number, frequency (daily or occasionally) and duration of the habit. ${ }^{12}$
BMI was calculated by dividing body weight $(\mathrm{kg})$ by height $(\mathrm{m})$ squared. ${ }^{13}$ Body weight was measured using a weighing scale (180 kg capacity; 100 precision), and height was measured using a stadiometer (graduated in $\mathrm{cm}$ ), with maximum height measurement of $200 \mathrm{~cm}$.

Waist circumference was measured using a measuring tape at the smallest point between the rib and the iliac crest (hip bone). Abdominal circumference was determined at the midpoint between the tenth rib and the iliac crest, and hip at the maximum protrusion of the gluteal region. ${ }^{14}$

Blood pressure was measured using a semi-automated, digital device, from the individual at rest, in sitting position. Three measures were taken, with a minimal interval of one minute between them, and the mean of these measurements was considered for analysis.

Metabolic syndrome was defined according to the World Health Organization (WHO), the National Cholesterol Education Program (NCEP) and the International Diabetes Federation (IDF) criteria. According to the WHO, MS was defined as the presence of diabetes, glucose intolerance or insulin resistance, in addition to two or more of the following: central obesity (waist-to -hip ratio $>0.90$ in men and $>0.85$ in women, and / or BMI $\geq 30 \mathrm{~kg} / \mathrm{m}^{2}$; systolic blood pressure $\geq$ 140 or diastolic blood pressure $\geq 90 \mathrm{mmHg}$ or treatment for hypertension; plasma triglycerides $\geq 150 \mathrm{mg} / \mathrm{dL}$ or HDL cholesterol $<35 \mathrm{mg} / \mathrm{dL}$ in men and $<39 \mathrm{mg} / \mathrm{dL}$ in women. ${ }^{13}$

For NCEP, MS was defined as the presence of three or more of the following: glucose $>110 \mathrm{mg} / \mathrm{dL}$; central obesity (waist circumference $>102 \mathrm{~cm}$ in men and $>$ $88 \mathrm{~cm}$ in women); systolic blood pressure $\geq 130$ or diastolic blood pressure $\geq 85 \mathrm{mmHg}$; plasma triglycerides $\geq 150 \mathrm{mg} / \mathrm{dL}$ or HDL cholesterol $<40 \mathrm{mg} / \mathrm{dL}$ in men and $<50 \mathrm{mg} / \mathrm{dL}$ inn women. ${ }^{15}$

The International Diabetes Federation criteria for MS consider waist circumference $>90 \mathrm{~cm}$ in men and $>80 \mathrm{~cm}$ in women together with the presence of two or more of the following: glucose $\geq 100 \mathrm{mg} / \mathrm{dL}$ or previous diagnosis of diabetes, triglycerides $\geq 150 \mathrm{mg} / \mathrm{dL}$ or treatment for dyslipidemia, HDL cholesterol $<40 \mathrm{mg} / \mathrm{dL}$ in men or $<50$ $\mathrm{mg} / \mathrm{dL}$ in women or treatment for dyslipidemia, systolic blood pressure $\geq 130 \mathrm{mmHg}$ or diastolic blood pressure $\geq 85 \mathrm{mmHg}$ or treatment for hypertension. ${ }^{16}$

Cardiovascular risk was determined according to the Framingham risk score - a low, intermediate or high 10 -year risk were defined as a risk $\leq 10 \%, 10-20 \%$ and $\geq$ 
$20 \%$, respectively, for coronary heart disease, based on sex, age, HDL and LDL cholesterol levels, systolic and diastolic blood pressure, diabetes and smoking. ${ }^{17}$

An informed consent form, containing detailed information about the study, and assuring confidentiality and protection from harm or complications, was signed by each participant or their tutors. The study was submitted and approved by the ethics committee of Piauí Federal University.

\section{Statistical analysis}

We conducted a descriptive, analytical study. Categorical data were expressed as relative (\%) and absolute (n) frequency, and 95\% confidence interval. Distribution of quantitative variables was tested for normality using the Kolmogorov-Smirnov test. Continuous variables with normal distribution were presented as dispersion measures (mean and standard deviation) and measures of central tendency (minimum and maximum values).

The null hypothesis ( $\mathrm{H} 0)$ was that the data had a normal distribution, whereas the alternative hypothesis (H1) was that data did not have a normal distribution (Kolmogorov test). Student's t-test was used for comparisons of the means of data with normal distribution, and the non-parametric Mann-Whitney U test used for data without normal distribution (rejecting the null hypothesis).

To verify whether the variables were independent (i.e., unrelated), we used the chi-square test of independence and the Fisher's exact test (when more than $25 \%$ of the expected frequency was lower than 5 or if any of the expected frequencies was lower than 1). The odds ratio was used to test the strength of the association between two variables. The level of significance was set at 0.05 .

Data were organized and analyzed using the IBM Statistical Package for the Social Sciences software, version 20.0.18

\section{Results}

A total of 298 individuals participated in the study, $176(59.1 \%)$ were women. Most men $(57.38 \%)$ were aged between 18 and 40 years, and most women $(55.11 \%)$ between 40 and 60 years. Most participants (65.4\%) selfreported "Pardo". Regarding school attainment, $46 \%$ completed elementary school, $75.9 \%$ were single, living with family members, and $36.2 \%$ of them gained $<1$ minimum wage (Table 1).

The frequency of MS was 5.4\%, 41.3\% and $46 \%$ according to the WHO, NCEP and IDF criteria, respectively. A higher frequency of MS was seen among women according to these three definitions, although a statistically significant difference between men and women was seen with the NCEP criteria only $(\mathrm{p}=0.0094)$ (Table 2).

Schizotypal disorders and persistent delusional disorders were the most prevalent conditions $(50 \%$; $60.7 \%$ in men), followed by mood disorders $(39.3 \% ; 50.0 \%$ in women). No cases of behavioral syndromes, disorders of adult personality and behavior, intellectual disabilities, or psychological developmental disorders were found. A higher frequency of MS was observed in patients with schizotypal disorders and persistent delusional disorders - 50\%, $47.2 \%$ and $48.2 \%$ according to WHO, NCEP and IDF criteria, respectively (Table 3).

In addition, regarding the 10-year risk for coronary diseases, most patients $(81.9 \%)$ showed a low cardiovascular risk, $13.8 \%$ and intermediate risk, and $4.4 \%$ a high risk. Therefore, an intermediate or a high cardiovascular risk was seen in $18.12 \%$ of the sample, $75.07 \%$ among women.

The factors used for the Framingham score calculation are described in Table 4 . All variables were significantly associated with cardiovascular risk, except for smoking.

Significant association between the variables was found in the analysis of the relationship of the intermediate/high risk for coronary disease with MS $(\mathrm{p}<0,01)$. Analysis of the data revealed that the chance of individuals with MS, according to the WHO criteria, being at an intermediate or high risk for cardiovascular disease was 12.22 times greater than those without MS, and 8.01 and 6.23 times greater based on NCEP and IDF criteria for MS, respectively (Table 5).

\section{Discussion}

Although many studies have investigated MS or cardiovascular risk in psychiatric patients, ${ }^{19-21}$ this is the first study to evaluate the classification of cardiovascular risk and its association with MS in MD patients at secondary health care in Brazil.

The present study confirmed data in the literature showing an association between MDs and social indicators, such as a higher frequency of female 
Table 1 - Sociodemographic profile of the study population by sex

\begin{tabular}{|c|c|c|c|c|c|}
\hline \multirow[b]{3}{*}{ Age } & \multicolumn{4}{|c|}{ Sex } & \multirow{3}{*}{$\begin{array}{c}\begin{array}{c}\text { Total } \\
(\mathrm{n}=298)\end{array} \\
\mathrm{n}(\%)\end{array}$} \\
\hline & \multicolumn{2}{|c|}{ Male $(n=122)$} & \multicolumn{2}{|c|}{ Female $(n=176)$} & \\
\hline & $\mathbf{N}$ & $\%$ & $\mathbf{N}$ & $\%$ & \\
\hline$>18 \mathrm{e}<40$ & 70 & $(57.38)$ & 58 & (32.95) & $128(42.95)$ \\
\hline$>40 \mathrm{e}<60$ & 46 & $(37.70)$ & 97 & $(55.11)$ & $143(47.99)$ \\
\hline$>60 \mathrm{e}<74$ & 6 & $(4.92)$ & 21 & (11.93) & $27(9.06)$ \\
\hline \multicolumn{6}{|l|}{ Race } \\
\hline White & 10 & $(8.2)$ & 12 & (6.8) & $22(7.4)$ \\
\hline Pardo & 69 & $(56.6)$ & 126 & $(71.6)$ & $195(65.4)$ \\
\hline Black & 43 & $(35.2)$ & 38 & $(21.6)$ & $81(27.2)$ \\
\hline \multicolumn{6}{|l|}{ School attainment } \\
\hline Illiterate & 12 & $(9.8)$ & 7 & $(4.0)$ & $19(6.4)$ \\
\hline Literate & 6 & $(4.9)$ & 3 & $(1.7)$ & $9(3.0)$ \\
\hline Elementary school & 60 & $(49.1)$ & 77 & $(43.8)$ & $137(46.0)$ \\
\hline High school & 37 & $(30.4)$ & 83 & $(47.1)$ & $120(40.2)$ \\
\hline Higher education & 7 & $(5.7)$ & 6 & (3.4) & $13(4.4)$ \\
\hline \multicolumn{6}{|l|}{ Civil status } \\
\hline Living with a partner (with/without children) & 8 & $(6.6)$ & 43 & $(24.5)$ & $51(17.1)$ \\
\hline Living with family members (without a partner) & 110 & $(90.2)$ & 116 & $(65.9)$ & $226(75.9)$ \\
\hline Living with other people (without a partner) & 1 & $(0.8)$ & 5 & $(2.8)$ & $6(2.0)$ \\
\hline Living alone & 3 & $(2.5)$ & 12 & $(6.8)$ & $15(5.0)$ \\
\hline \multicolumn{6}{|l|}{ Income } \\
\hline No income & 3 & $(2.5)$ & 7 & $(4.0)$ & $10(3.4)$ \\
\hline$<1 \mathrm{MW}$ & 32 & $(26.2$ & 76 & $(43.2)$ & $108(36.2)$ \\
\hline$>1 \mathrm{MW}$ and $<2 \mathrm{MWs}$ & 39 & $(32.0)$ & 47 & $(26.7)$ & $86(28.9)$ \\
\hline$>2$ and $<3 \mathrm{MWs}$ & 29 & $(23.8)$ & 34 & $(19.3)$ & $63(21.1)$ \\
\hline$>3$ and $<5 \mathrm{MWs}$ & 15 & (12.3) & 8 & $(4.5)$ & $23(7.7)$ \\
\hline$>5 \mathrm{MWs}$ & 4 & (3.3) & 4 & (2.3) & $8(2.7)$ \\
\hline
\end{tabular}

patients, low educational attainment, low income, white ethnicity and single. ${ }^{22,23}$ With respect to age, in the study by Andrade et al., ${ }^{24}$ patients aged between 25 and 59 years were more likely to develop MDs. This would have a great impact on economy, since this age group represents the majority of the economically active population.

There is strong evidence that women have a higher propensity to seek health care than men. ${ }^{25}$ In addition, studies have indicated an association of MS with female 
Table 2 - Frequency of metabolic syndrome according to the World Health Organization, National Cholesterol Education Program and International Diabetes Federation criteria by sex

\begin{tabular}{|c|c|c|c|c|c|c|c|}
\hline \multirow[b]{3}{*}{ Qualitative variables } & \multicolumn{4}{|c|}{ Sex } & \multirow{2}{*}{\multicolumn{2}{|c|}{ Total $(n=298)$}} & \multirow{3}{*}{ p-value } \\
\hline & \multicolumn{2}{|c|}{ Male $(n=122)$} & \multicolumn{2}{|c|}{ Female $(n=176)$} & & & \\
\hline & $\mathbf{N}$ & $\%$ & $\mathbf{N}$ & $\%$ & $\mathbf{N}$ & $(\%)$ & \\
\hline \multicolumn{8}{|l|}{ MS - WHO } \\
\hline No & 118 & $(96.7)$ & 164 & $(93.2)$ & 282 & (94.6) & 0.2839 \\
\hline Yes & 4 & $(3.3)$ & 12 & (6.8) & 16 & $(5.4)$ & \\
\hline \multicolumn{8}{|l|}{ MS - NCEP } \\
\hline No & 83 & $(68.0)$ & 92 & $(52.3)$ & 175 & $(58.7)$ & $0.0094^{* *}$ \\
\hline Yes & 39 & $(32.0)$ & 84 & $(47.7)$ & 123 & $(41.3)$ & \\
\hline \multicolumn{8}{|l|}{ MS - IDF } \\
\hline No & 74 & $(60.7)$ & 87 & $(49.4)$ & 161 & $(54.0)$ & 0.056 \\
\hline Yes & 48 & (39.3) & 89 & (50.6) & 137 & $(46.0)$ & \\
\hline
\end{tabular}

sex. The causes of such association have not been defined, although there are evidences of a social and biological predisposition, in which both neuroendocrine and social play a role in increasing the susceptibility in women. ${ }^{26}$ Besides, women are generally more influenced by psychological and hormonal factors. ${ }^{27}$ On the other hand, some authors have not found an association between sex and MS, indicating the need for further investigations, aiming at better elucidating the relationship between these variables. ${ }^{28,29}$

Educational attainment is known to contribute to a better quality of life, in addition to influence healthy behaviors. Consequently, it can improve the access of patients to healthcare, facilitating the early identification of health changes, including metabolic ones, and timely treatment. ${ }^{30}$

Job instability, low salaries, and lack of social benefits and protection of labor laws can contribute to the development of anxiety and depression among informal workers or unemployed individuals. ${ }^{31}$ These factors could explain the relatively higher frequency of individuals with a low family income in our study. Also, being a member of lower income families is associated with the incidence of and mortality for cardiovascular diseases, probably due to the combination of risk factors. ${ }^{32}$
Although the purpose of the present study was not to analyze specific diagnosis of the study population, Gonçalves et al., ${ }^{22}$ have reported the high prevalence of anxiety disorders in Brazil and attribute this finding to the generalized urban violence and adverse socioeconomical conditions. Besides, the high levels of noise and the lack of recreational areas in Brazilian big cities may be also be related. ${ }^{22}$

The prevalence of MS was markedly different considering the different evaluation criteria, i.e., WHO, NCEP and IDF's. The lower frequency of MS by the WHO criteria compared with NCEP and IDF criteria is explained by the fact that diabetes mellitus was considered a criterion for MS definition by the WHO only.

Regarding investigations on the prevalence of MS in patients with MT, Teixeira et al., ${ }^{33}$ conducted a systematic review of MS prevalence in patients with schizophrenia and schizotypal disorders. The review included eleven studies, with a prevalence varying from $28.4 \%$ to $62.5 \%$ (NCEP) in 9 studies. The lowest prevalence (28.4\%) was observed in a study conducted in the Netherlands, which was twice the prevalence of MS in the general population in the country, according to the authors. ${ }^{33}$

Similar to recent studies, ${ }^{34,35}$ the present study confirm the increased prevalence of MS among women with 
Table 3 - Prevalence of metabolic syndrome by psychiatric diagnosis

\begin{tabular}{|c|c|c|c|c|c|c|c|}
\hline \multirow{4}{*}{$\begin{array}{l}\text { Psychiatric } \\
\text { diagnostic groups }\end{array}$} & \multicolumn{6}{|c|}{ Metabolic syndrome } & \multirow{3}{*}{ Total } \\
\hline & \multicolumn{2}{|c|}{ WHO } & \multicolumn{2}{|c|}{ NCEP } & \multicolumn{2}{|c|}{ IDF } & \\
\hline & Yes & No & Yes & No & Yes & No & \\
\hline & $\begin{array}{c}N \\
(\%)\end{array}$ & $\begin{array}{c}\mathrm{N} \\
(\%)\end{array}$ & $\begin{array}{c}N \\
(\%)\end{array}$ & $\begin{array}{c}\mathrm{N} \\
(\%)\end{array}$ & $\begin{array}{c}N \\
(\%)\end{array}$ & $\begin{array}{c}\mathrm{N} \\
(\%)\end{array}$ & $\begin{array}{c}\mathrm{N} \\
(\%)\end{array}$ \\
\hline \multirow[t]{2}{*}{ Organic MDs* } & 0 & 2 & 1 & 1 & 1 & 1 & 2 \\
\hline & $(0.0)$ & $(0.7)$ & $(0.7)$ & $(0.6)$ & $(0.7)$ & $(0.6)$ & $(0.7)$ \\
\hline \multirow[t]{2}{*}{ Schizotypal MDs* } & 8 & 141 & 58 & 91 & 66 & 83 & 149 \\
\hline & $(50.0)$ & $(50.0)$ & $(47.2)$ & $(52.0)$ & $(48.2)$ & $(51.6)$ & $(50.0)$ \\
\hline \multirow[t]{2}{*}{ Mood disorders } & 7 & 110 & 53 & 64 & 58 & 59 & 117 \\
\hline & $(43.8)$ & $(39.0)$ & $(43.1)$ & $(36.6)$ & $(42.3)$ & $(36.6)$ & (39.3) \\
\hline \multirow[t]{2}{*}{ Neurotic disorders } & 1 & $7(2.5)$ & 4 & 4 & 4 & 4 & 8 \\
\hline & $(6.2)$ & $(2.5)$ & (3.3) & $(2.3)$ & $(2.9)$ & $(2.5)$ & $(2.7)$ \\
\hline \multirow[t]{2}{*}{ Intellectual disabilities } & 0 & 17 & 4 & 13 & 4 & 13 & 17 \\
\hline & $(0.0)$ & $(6.0)$ & (3.3) & $(7.4)$ & $(2.9)$ & $(8.1)$ & (5.7) \\
\hline \multirow[t]{2}{*}{ Unspecified } & 0 & 5 & 3 & 2 & 4 & 1 & 5 \\
\hline & $(0.0)$ & (1.8) & $(2.4)$ & $(1.1)$ & (2.9) & $(0.6)$ & (1.7) \\
\hline \multirow[t]{2}{*}{ Total } & 16 & 282 & 123 & 175 & 161 & 137 & 298 \\
\hline & (5.4) & (94.6) & (41.3) & (58.7) & $(46.0)$ & $(54.0)$ & (100.0) \\
\hline
\end{tabular}

MDs, especially in schizophrenic patients compared with patients with other psychiatric disorders. ${ }^{34,35}$

The higher prevalence of MS in psychiatric patients is explained by the fact that the cause of the MS is multifactorial, including factors related to life style (healthy eating and sedentarism), genetics, perinatal, neurochemical and hormonal factors, in addition to side effects of psychopharmaceuticals, such as dyslipidemia, insulin resistance, hyperglycemia and weight gain. ${ }^{6}$

The prevalence of risk factors for cardiovascular disease, including MS in patients with MDs is high. However, some of these risk factors are modifiable and could prevent many of the deaths caused by these conditions. ${ }^{36}$

Surprisingly, smoking was not significantly associated with cardiovascular risk classification. This may be due to the considerable decrease in the percentage of smokers in Brazil in the last decades as a result of several actions of the National Tobacco Control Policy in Brazil.37 Thus, the possibility that psychiatric patients are included in this percentage cannot be ruled out.

The prediction of cardiovascular risk in cardiovascular prevention has been well explored in the last decades.38 Estimation of the 10-year absolute risk of cardiovascular risk in primary and secondary prevention enables the development of preventive measures, particularly by guiding population strategies and detection of high risk individuals. Also, it can motivate treatment adherence and modulate risk reduction efforts. ${ }^{39}$

According to the World Heart Federation, ${ }^{40}$ men are more likely to develop cardiovascular diseases than women, but the risk increases in post-menopausal women and is practically the same as in men. This could explain the higher prevalence of high cardiovascular risk 
Table 4 - Clinical and laboratory data by ten-year cardiovascular risk classification (Framingham risk score) in individuals with psychiatric disorders

\begin{tabular}{ccc} 
Cardiovascular risk & & p-value \\
\hline Low & Intermediate & High \\
$(\mathrm{n}=244)$ & $(\mathrm{n}=41)$ & $(\mathrm{n}=13)$
\end{tabular}

Sex

\section{Male}

Female

Age

LDL cholesterol

HDL cholesterol

Systolic blood pressure

Diastolic blood pressure

Glycemia

(53 - 274)

$196(65.8)$

$48(16.1)$

No
$10(8.2)$

31 (17.6)

$55.6 \pm 8.76$

$(24-79)$

$169 \pm 105.2$

(97.2 - 608)

$42.7 \pm 11.3$

(24 - 85)

$121.7 \pm 24.2$

$(85-230)$

$78.5 \pm 9.68$

$(57-100)$

$101.6 \pm 40.8$

(46 - 318)

33 (11.1)

8 (2.7)
4 (3.3)

0.042 *

$9(5.1)$

$59.9 \pm 8.53$

$<0.001^{* *}$

(44 - 76)

$143.5 \pm 50.2$

$<0.001^{\text {** }}$

(67.2 - 241)

$37.1 \pm 8.06$

$0.003^{* *}$

(26 - 51)

$118 \pm 11.1$

$0.003^{* *}$

(102 - 140)

$73.3 \pm 18.1$

$0.013^{*}$

(51 - 115)

$111.4 \pm 26.5$

$<0.001^{\text {** }}$

(71 - 146)

$4(1.3)$

Chi-square test, Fisher's exact test, Mann-Whitney test; *Statistically significant at 5\%; ** Statistically significant at $1 \%$.

Table 5 - Association between metabolic syndrome and moderate or high risk for cardiovascular diseases in patients with mental disorders

\begin{tabular}{|c|c|c|c|c|}
\hline \multicolumn{5}{|c|}{ Intermediate / high cardiovascular risk } \\
\hline Classification of MS & $\mathbf{N}(\%)$ & p-value & OR & $95 \% \mathrm{CI}$ \\
\hline OMS & $11(68.8 \%)$ & $<0.01$ & 12.228 & $4.047-36.951$ \\
\hline NCEP & $43(35.0 \%)$ & $<0.01$ & 8.014 & $3.924-16.367$ \\
\hline IDF & $43(31.4 \%)$ & $<0.01$ & 6.238 & $3.065-12.696$ \\
\hline
\end{tabular}


in women than men in our study, since mean age was higher in the former than in the latter.

Based on the Framingham Heart Study, it is important to consider the percentage of intermediate / high risk for cardiovascular diseases in our study population. Although apparently low - 18.12\% the percentage was meaningful considering the importance of the diagnosis. Besides, this result cannot be compared with that reported in previous studies and populations, since our study is a pioneer study on the theme.

The chance of the patients diagnosed with MS be at intermediate/high risk for cardiovascular disease was elevated according to the three evaluation criteria for MS. In addition, it is worth pointing out that, although the IDF criteria have been the most widely described in the literature, despite the most conservative, the WHO criteria were the most sensitive in showing that individuals with MS were at intermediate/high risk for cardiovascular disease.

Considering these data and the study by Tseng et al., ${ }^{21}$ which showed a higher prevalence not only of MS but also of cardiovascular disease in individuals with MDs, it is reasonable to suggest that the percentage of intermediate/ high risk for cardiovascular disease and of cardiovascular risk is higher in psychiatric population as compared with the general population.

Limitations of the study correspond to limitations of the Framingham risk score, including - the absolute cardiovascular risk in participants in the Framingham study is not necessarily the same that observed in other populations; some risk factors known to be important in cardiovascular diseases were not considered in the development of the score such as diet, body weight and physical exercise; finally, the risk has a one-way relationship, i.e. the reduction in one risk factor does not necessarily reduces cardiovascular risk. In addition, differences in the cut-off points for the risk factors used by the different MS criteria may be a source of bias between the associations. Also, limitations intrinsic of crosssectional studies make it difficult to establish a causal relationship, in this case, between risk factor exposure and development of disease.

Although much effort has been devoted to determine the risk factors to which the psychiatric population are exposed, there are still many challenges to guarantee the right to health for this population. These data can serve as a basis for the planning of actions that contribute to increase life expectancy and improve the quality of life of these patients.

\section{Conclusion}

Our findings confirm the sociodemographic profile of social disadvantage and the vulnerability for cardiovascular risk factors in patients attending CAPSs.

The prevalence of MS, established by the NCEP and the IDF diagnostic criteria, was high in this population, especially in patients with schizotypal disorders. In addition, our results indicate a high prevalence of intermediate/high cardiovascular risk in psychiatric patients and its significant association with MS.

\section{Acknowledgments}

We thank Teresina Municipal Health Foundation for acknowledging the importance of the study and for granting authorization for its conception. We thank the patients and the staff of the Psychosocial Care Center of the southeast region in Teresina, Brazil, for their decisive contribution to this study.

\section{Author contributions}

Conception and design of the research: Cabral SMR, Santos MM. Acquisition of data: Cabral SMR. Analysis and interpretation of the data: Cabral SMR, Santos MM. Writing of the manuscript: Cabral SMR. Critical revision of the manuscript for intellectual content: Cabral SMR, Santos MM.

\section{Potential Conflict of Interest}

No potential conflict of interest relevant to this article was reported.

\section{Sources of Funding}

The authors declare there was no external funding for the study, except for the materials used for blood sample collection, which were provided at no charge by Raul Bacelar Laboratory of Teresina municipal health system, Brazil.

\section{Study Association}

This article is part of the thesis of master submitted by Sarah de Melo Rocha Cabral, from Universidade Federal do Piauí. 


\section{Ethics approval and consent to participate}

This study was approved by the Ethics Committee of the Universidade Federal do Piauí under the protocol number 985.376 . All the procedures in this study were in accordance with the 1975 Helsinki Declaration, updated in 2013. Informed consent was obtained from all participants included in the study.

\section{References}

1. Brasil. Ministério da Saúde. Secretaria de Atenção à Saúde, Departamento de Ações Programáticas Estratégicas. Reforma psiquiátrica e política de saúde mental no Brasil. In: Conferência Regional de Reforma dos Serviços de Saúde Mental:15 anos depois de Caracas/OPAS. Brasília;2005

2. Brasil. Ministério da Saúde. Secretaria de Atenção à Saúde, Departamento de Ações Programáticas Estratégicas. Manual de estrutura física dos centros de atenção psicossocial e unidades de acolhimento: orientações para elaboração de projetos de construção de CAPS e de UA como lugares da atenção psicossocial nos territórios. Brasília;2013.

3. Bernardi AB, Kanan LA. Características dos serviços públicos de saúde mental (Capsi, Capsad, Caps III) do estado de Santa Catarina. Saúde Debate 2015; 39(107):1105-16.

4. Garcia PCO, Moreira JC, Bissoli MC, Simões TMR. Perfil nutricional de indivíduos com transtorno mental, usuários do Serviço Residencial Terapêutico, do município de Alfenas - MG. Rev Univ Vale do Rio Verde 2013 jan-jul;11(1):114-26.

5. Saloojee S, Burns JK, Motala AA. Metabolic syndrome in South African patients with severe mental lllness: prevalence and associated risk factors. PLoS ONE. 2016;11(2):1-14

6. Łopuszańska, UJ, Skorzyńska-Dziduszko K, Lupa-Zatwarnicka K, Makara-Studzińska M. Mental illness and metabolic syndrome - a literature review. Ann Agric Environ Med. 2014;21(4):815-21.

7. Simao AF, Precoma DB, Andrade JP, Correa Filho H, Saraiva JFK, Oliveira GMM, et al.,Sociedade Brasileira de Cardiologia. I Diretriz brasileira de prevenção cardiovascular. Arq Bras Cardiol. 2013;101(6 supl 2):1-63.

8. Grover S, Nebhinani N, Chakrabarti S, Avasthi A, Basu D, Kulhara P, et al. Cardiovascular risk factors among bipolar disorder patients admitted to an inpatient unit of a tertiary care hospital in India. Asian J Psychiatr. 2014 aug; 10:51-5.

9. Speyer, H, Nørgaard HC, Hjorthøj C, Madsen TA, Drivsholm S, Pisinger C, et al. Protocol for CHANGE: a randomized clinical trial assessing lifestyle coaching plus care coordination versus care coordination alone versus treatment as usual to reduce risks of cardiovascular disease in adults with schizophrenia and abdominal obesity. BMC Psychiatry. 2015;15(119):1-11.

10. Thompson, SK. Sampling. New York:John Wiley;1992.

11. Organização Mundial da Saúde. CID-10: classificação estatística internacional de doenças e problemas relacionados à saúde. 10 ed. rev. São Paulo: Universidade de São Paulo; 1997. v.1.

12. Brasil. Ministério da Saúde (BR), Secretaria de Vigilância em Saúde, Departamento de Vigilância de Doenças e Agravos não Transmissíveis e Promoção da Saúde. Vigitel Brasil 2014: vigilância de fatores de risco e proteção para doenças crônicas por inquérito telefônico. Brasília;2015.

13. World Health Organization. Definition, diagnosis and classification of diabetes mellitus and its complications: report of a WHO consultation. Part 1: diagnosis and classification of diabetes mellitus. Geneva;1999.

14. Brasil. Ministério da Saúde (BR), Secretaria de Atenção à Saúde, Departamento de Atenção Básica. Orientações para a coleta e análise de dados antropométricos em serviços de saúde: norma técnica do Sistema de Vigilância Alimentar e Nutricional - SISVAN. Brasília;2011.
15. National Cholesterol Education Program. Third Report of the National holesterol Education Program (NCEP). Expert Panel on Detection, Evaluation, and Treatment of High Blood Cholesterol in Adults (Adult Treatment Panel III) final report. Circulation. 2002;106(25):3143-421.

16. International Diabetes Federation. IDF worldwide definition of the metabolic syndrome [internet]. [Acesso em 2006 set 06]. Disponível em: http:/ / www.idf.org/metabolic-syndrome.

17. Brasil. Ministério da Saúde (BR), Secretaria de Atenção à Saúde, Departamento de Atenção Básica. Prevenção clínica de doenças cardiovasculares, cerebrovasculares e renais. Brasília; 2006.

18. International Business Machine. Released 2011. IBM SPSS Statistics for Windows, Version 20.0. Armonk, NY: IBM Corp; 2011.

19. Sood PG, Lally J, Smith S, Atakan Z, Ismail K, Greenwood KE, et al. Cardiovascular risk factors and metabolic syndrome in people with established psychotic illnesses: baseline data from the IMPaCT randomized controlled trial. Psychol Med. 2015;45(1):2619-29.

20. Kamkar MZ, Sanagoo A, Zargarani F, Jouybari L, Marjani A. Metabolic syndrome in patients with severe mental illness in Gorgan. J Nat Sci Biol Med. 2016;7(1):62-7.

21. Tseng PT, Wang HY, Cheng YS, Shen FC, Lin PY, Wu CK. The metabolic syndrome and risk of coronary artery disease in patients with chronic schizophrenia or schizoaffective disorder in a chronic mental institute. Kaohsiung J Med Sci. 2014;30(1):579-86.

22. Gonçalves DA, Mari JJ, Bower P, Gask L,Dowrick C, Tófoli LF, et al. Brazilian multicentre study of common mental disorders in primary care: rates and related social and demographic factors. Cad Saúde Pública. 2014;30(3):623-32.

23. Kaspper LS, Schermann LB. Prevalência de transtornos mentais comuns e fatores associados em usuárias de um Centro de Referência de Assistência Social de Canoas/RS. Aletheia $2014 \mathrm{dez} ;$ 1(45):168-76.

24. Andrade LHSG, Lolio CA, Gentil Filho V, Laurenti R. Epidemiologia dos transtornos mentais em uma área definida de captação da cidade de São Paulo, Brasil. Rev Psiquiatr Clin 1999 set-out; 26(5):257-61.

25. Silva CHN, Monteiro AM, Sbroggio Júnior AL, Silva WJ, D'Affonsico GBC, Guarienti WD. Revisão sistemática da prevalência de depressão na diabetes mellitus tipo 2. Rev Univ Vale Rio Verde 2016 jul; 13(1):136-41.

26. Gonçalves DM, Kapczinski F. Prevalência de transtornos mentais em indivíduos de uma unidade de referência para Programa Saúde da Família em Santa Cruz do Sul, Rio Grande do Sul, Brasil. Cad Saúde Pública 2008; 24(1):2043-53.

27. Santos CE, Schrank Y, Kupfer R. Análise crítica dos critérios da OMS, IDF e NCEP para síndrome metabólica em pacientes portadores de diabetes melito tipo 1. Arq Bras Endocrinol Metab. 2009; 53(9):1096-102.

28. Scott KM, Von Korff M, Alonso J, Angermeyer MC, Bromet E, Fayyad J, et al. Mental-physical comorbidity and its relationship with disability: results from the World Mental Health Surveys. Psychol Med.2009;39(1):33-43.

29. Silva DAD, Salvo VLMA. Prevalência de síndrome metabólica e critérios diagnósticos: revisão. Rev Bras de Obesidade, Nutrição e Emagrecimento (RBONE) 2011;5(28):284-94. 
30. Makara-Studzińska M, Wołyniak M, Partyka I. The quality of life in patients with schizophrenia in community mental health service selected factors. J Pre-Clin Clin Res. 2011;5(1):31-4.

31. Azevedo JMM, Zuardi AW. COOP/WONCA charts as a screen for mental disorders in primary care. Ann Fam Med. 2011;9(1):359-65.

32. Cruz, IRD, Freitas DA, Soares WD, Mourão DM, Aidar FJ, Carneiro AL. Síndrome metabólica e associação com nível socioeconômico em escolares. Rev CEFAC. 2014;16(4):1294-302.

33. Teixeira PJ, Rocha FL. Associação entre síndrome metabólica e transtornos mentais. Rev Psiq Clín. 2007;34(1):28-38.

34. Lasic D, Bevanda M, Bošnjak N, Uglešić B, Glavina T, Franić T. Metabolic syndrome and inflammation markers in patients with schizophrenia and recurrent depressive disorder. Psychiatr Danub. 2014;26(3):214-9.

35. Bly MJ, Taylor SF, Dalack G, Pop-Busui R, Burghardt KJ, Evans SJ, et al. Metabolic syndrome in bipolar disorder and schizophrenia: dietary and lifestyle factors compared to the general population. Bipolar Disord. 2014;16(3):277-88.
36. Azad, MC, Shoesmith WD, Al Mamun M, Abdullah AF, Naing DK, Phanindranath $\mathrm{M}$, et al. Cardiovascular diseases among patients with schizophrenia. Asian J Psychiatr fev 2016; 19:28-36.

37. Brasil. Instituto Nacional do Câncer. Prevalência de tabagismo [internet]. [acesso em 2016 jun 28]. Disponível em: http:// www2.inca.gov. br/wps/wcm/connect/observatorio_controle_tabaco/site/home/ dados_numeros/prevalencia-de-tabagismo.

38. Rocha E. Scores de risco cardiovascular: utilidade e limitações. Rev Port Cardiol. 2008;35(1):15-8.

39. Lotufo PA. O escore de risco de Framingham para doenças cardiovasculares. Rev Med. 2008;87(4):232-7.

40. World Heart Federation. Cardiovascular disease risk factor [internet]. 2016 [acesso em 2016 jun 7].Disponível em: www.world-heart-federation. org/cardiovascular-health/ cardiovascular-disease-risk-factors. 